\title{
In vitro and In vivo Evaluation of the Wound Healing Potential of the Extracts of Schinus molle L. (Anacardiaceae) Grown in Jordan
}

\begin{abstract}
NOUR ABOALHAIJA ${ }^{1}$, FATMA AFIFI ${ }^{2}$, MAYSA AL-HUSSAINI ${ }^{3}$, M. AL-NAJJAR ${ }^{2}$, RANA ABU-DAHAB ${ }^{4}$, ELIZA HASEN $^{2}$, MAHA $^{2}$ RASHED ${ }^{4}$, SARA ABDEL HAQ ${ }^{5}$ AND E. KHALIL ${ }^{5 *}$

Department of Pharmaceutical Sciences, School of Pharmacy, The University of Jordan, Amman, ${ }^{1}$ Department of Pharmaceutical Sciences, Faculty of Pharmacy, Al-Zaytoonah University of Jordan, Amman, ${ }^{2}$ Department of Pharmaceutical Chemistry and Pharmacognosy, Faculty of Pharmacy, Applied Science Private University, Amman, ${ }^{3}$ King Hussein Cancer Centre, Amman, ${ }^{4}$ Biopharmaceutics and Clinical Pharmacy, School of Pharmacy, The University of Jordan, Amman, ${ }^{5}$ Department of Pharmaceutics and Pharmaceutical Technology, School of Pharmacy, The University of Jordan, Amman, Jordan
\end{abstract}

\section{Aboalhaija et al.: Wound Healing Potential of Schinus molle L}

\begin{abstract}
The aim of this study was to assess the wound healing potential of Schinus molle L. aqueous and ethanol extracts. First, the antimicrobial activity of Schinus molle extracts was tested against six microorganisms (Staphylococcus aureus, Escherichia coli, Pseudomonas aeruginosa, Staphylococcus epidermidis, Enterococcus faecalis and Citrobacter freundii). The growth of Citrobacter freundii and Enterococcus faecalis was totally inhibited by the aqueous extract at the lowest tested concentration $(1.56 \mathrm{mg} / \mathrm{ml})$. Next, in vitro wound healing assays were performed using human fibroblast cells' proliferation and scratch tests. Based on the obtained promising results, the aqueous extracts were further tested in an in vivo excision wound model in rats. Animals were treated with a hydrogel formula enriched with the plant aqueous extract in two different concentrations ( $2 \%$ and $5 \%$ ). Re-epithelialization, fibrosis and neovascularization of the epidermis and sub-epidermal cells in the regenerated tissue was observed, accompanied by an increase in the tensile strength of the skin of the rats treated with the plant aqueous extract when compared to the negative control group. Our results strongly support the use of Schinus molle aqueous extracts in topical formulations to promote wound healing.
\end{abstract}

Key words: Schinus molle L., Anacardiaceae, wound, Jordan, antimicrobial, in vitro, in vivo

The primary function of the skin is to serve as a protective barrier against the environment. Losing the integrity of large portions of the skin as a result of injury or illness may lead to major disability or even death $^{[1]}$. The severity of the injury ranges from acute to traumatic. The traumatic injury is one of the leading causes of mortality worldwide. In addition, millions of surgical wounds are created yearly due to routine medical care. Facilitating the healing of these injuries and restoring the tissue function remains a fundamental concern of clinical care. Although minor injuries in healthy individuals generally heal well, larger injuries or the presence of a certain physiological or common disease states including age, infection, vascular disease, diabetes and cancer can negatively affect the healing process in ways still poorly understood ${ }^{[2]}$.

Wound healing is a complex process with many potential factors that can delay healing ${ }^{[3]}$. There is increasing

*Address for correspondence

E-mail: ekayoub@ju.edu.jo interest to study the effects of bacteria on the processes of wound healing, because all chronic wounds are colonized by bacteria, with low levels of bacteria being beneficialtothewoundhealingprocess ${ }^{[4]}$. Theprogression from wound colonization to infection depends not only on the bacterial count or the species present, the number of different microorganisms species present, the virulence of the organisms and synergistic interactions between the different species, but also on the host immune response. So far, antiseptics and antibiotics have continued to provide a wealth of wound healing products. The intensive use of antibiotics and

\footnotetext{
This is an open access article distributed under the terms of the Creative Commons Attribution-NonCommercial-ShareAlike 3.0 License, which allows others to remix, tweak, and build upon the work non-commercially, as long as the author is credited and the new creations are licensed under the identical terms
}

Accepted 18 March 2021 Revised 11 February 2021 Received 08 October 2020 Indian J Pharm Sci 2021;83(2):261-270 
the misuse of antibiotics raised the flag of resistance; therefore, there is an urgent need to develop alternative treatment options for wound healing using natural sources such as plant extracts.

Schinus molle (S. molle) L., (Family Anacardiaceae), commonly known as pepper tree, pink pepper or Brazilian pepper, is an evergreen small tree or shrub that grows up $10 \mathrm{~m}$, with pink to reddish berries-like fruits of about $5 \mathrm{~mm}$ in diameter, narrow leaves and white-yellow flower clusters ${ }^{[5]}$. S. molle is originating from Peru and is distributed in other countries in South America and Central America. This evergreen tree with attractive and beautiful red fruits has been introduced to the Mediterranean area. It is widely planted on roadsides, in graveyards and gardens of North Africa and in Eastern Mediterranean countries, including Jordan as a shade tree ${ }^{[6-10]}$.

In the countries of origin, $S$. molle finds widespread utilization. The traditional use is covered by dozens of publications, supporting its use as an antiinflammatory ${ }^{[11]}$, anti-bacterial and anti-fungal active plant ${ }^{[6,10]}$ with anti-oxidant properties ${ }^{[12,13]}$. Specific attention is given to the wound-healing potential of this plant, supported by in vitro experiments ${ }^{[8,14-17]}$. Hydrogels take the shape of the wound once applied, have a high-water content and can thus hold moisture at the wound site; this offers ideal conditions for skin hydration, healing and removing necrotic tissue ${ }^{[18]}$. The intended formula has a liquid properties at room temperature, so can be easily handled and undergo gelling rapidly at body temperature so increase the contact time with the injured skin and makes a barrier layer above it. Recently, we reported the essential oil composition as well as anticholinesterase activity and antiproliferative potentials of the extracts of $S$. molle grown in Jordan ${ }^{[19,20]}$. The present study describes our attempts in evaluating the antimicrobial activity and the in vitro/in vivo wound healing potential of the aqueous and ethanol extracts of the dried aerial parts (leaves and fruits) of $S$. molle in form of hydrogel formulation.

\section{MATERIALS AND METHODS}

\section{Materials:}

For the evaluation of the antimicrobial activity nutrient broth (Oxoid city, UK), spectrophotometer (Milton Roy 601 from Milton Roy Company. USA), 96-microwell plate (Biofil, Barcelona, Spain), and enzyme-linked immunosorbent assay (ELISA) reader (Epoch, Biotek Instruments, USA) were used and Gentamicin (Hikma
Pharmaceuticals, Jordan) was used as a positive control.

The following compounds were used in the formula preparation: Chitosan 50,000 dalton (G.T.C union group 1td., Qingdao, China), Pluronic F-127 (Lutrol, Ludwigshafen, Germany), Hydroxyapatite (SigmaAldrich, St. Louis, USA) and glutaraldehyde (Tedia, Ohio, USA).

For in vitro wound healing characterization the following materials were used: Iscove's Modified Dulbecco's Medium (IMDM), Fetal bovine serum (FBS) and Bovine serum albumin (BSA), all obtained from Euroclone, Pero, Italy, Human Dermal Fibroblasts (HDF, CCD-1064Sk ATCC ${ }^{\circledR}$ CRL-2076 ${ }^{\mathrm{TM}}$, ATCC, Manassas USA), 96- and 6 well plates (Biofil, Barcelona, Spain), MTT assay kit (Sigma-Aldrich, St. Louis, USA), and ELISA reader (Sunrise Basic Sciences, Austria) and AxioCamICc 5 on primovert microscope (Zeiss, Oberkochen, Germany)

For in vivo wound healing characterization Ketamine (Tekam $50 \%$, Hikma, Jordan) and Xylazine (Xyalject $20 \%$, Adwia, Egypt) were used to anaesthetize the animals. Ialuset ${ }^{\circledR}$ Plus (Hyaluronic acid and Silver sulfadiazine, IBSA, USA) was obtained from a local pharmacy and used as a positive control in the wound healing experiment. Tensile strength of the healed skin was measured using Universal testing machine (UTM, $50 \mathrm{~N}$ loading cell, Shimadzu, Japan) and the skin samples thickness was measured using a digital caliper (Mitutoyo corporation, Japan). For histological studies, the skin samples were fixed in $4 \%$ paraformaldehyde and stained with hematoxylin/eosin (H\&E) or Masson's trichrome stain (Sigma-Aldrich, St. Louis, USA) and examined using 20x optical microscope (Olympus BX41, Japan).

\section{Extract preparation:}

Plant aerial parts were collected from Amman, Jordan, during summer 2018, identified using descriptive references ${ }^{[5,21]}$ and by comparison with herbarium specimens from the Department of Biological Sciences, School of Science, The University of Jordan. A voucher specimen has been deposited in the Department of Pharmaceutical Sciences, School of Pharmacy, University of Jordan, Amman, Jordan (FMJ-ANAC-3). Each ten grams of the dried fruits and leaves were mixed, added to $100 \mathrm{ml}$ of either distilled water, or 70 $\%$ ethanol and gently heated (to $70^{\circ}$ in case of water extract and $50^{\circ}$ to prepare the ethanolic extract) for $10 \mathrm{~min}$. The obtained extracts were covered and left overnight for complete extraction by soaking. The 
extracts were then filtered and evaporated to dryness using rotavapor (Buchi, Switzerland).

\section{Evaluation of the antimicrobial activity:}

The bacterial strains used in this study include Staphylococcus aureus (ATCC 25923), Escherichia coli (ATCC 14169), Pseudomonas aeruginosa (ATCC 27853), Staphylococcus epidermidis (ATCC 12228), Enterococcus faecalis (ATCC 29212) and Citrobacter freundii (ATCC 43864). They were freshly reconstituted from their lyophilized pellets in a freshly prepared sterilized nutrient broth and incubated at $37^{\circ}$ until the $\mathrm{OD}_{600}=0.4$ using a spectrophotometer, when the experiment started. The grown bacteria and the different treatments were prepared on a 96-microwell plate according to the following arrangement (triplicates for each treatment): (i) $300 \mu 1$ sterilized nutrient broth; (ii) $300 \mu 1$ of different concentration $(100,50,25,12.5$, $6.25,3.125,1.562 \mathrm{mg} / \mathrm{ml}$ ) for each extraction type (aqueous and ethanol); (iii) positive control (285 $\mu \mathrm{l}$ nutrient broth and $15 \mu 1$ of each bacteria; (iv) bacteria and plant extracts in specific concentrations in the following combinations: $150 \mu 1$ nutrient broth, $150 \mu 1$ plant extract in the 7 dilutions, $15 \mu \mathrm{l}$ bacteria. The plate was closed and then incubated in the incubator at $37^{\circ}$ for $24 \mathrm{~h}$ and after that the plate was measured using the ELISA reader that was adjusted to measure at $600 \mathrm{~nm}$. The final concentration of the bacteria was calculated by subtracting the absorbance of the sterilized broth and the plant extracts.

\section{In vitro wound healing characterization:}

Ten milligrams of the dried extracts were dissolved under sonication in $1 \mathrm{ml}$ Dimethyl sulfoxide (DMSO) to prepare stock solutions $(10 \mathrm{mg} / \mathrm{ml})$. For all in vitro experiments and in order to prepare the desired concentrations; the extract solutions were diluted using IMDM and the final concentration of DMSO did not exceed $0.1 \%$.

\section{Human dermal fibroblasts proliferation assay:}

Human dermal fibroblasts (HDF) proliferation assay of the ethanol and aqueous plant extracts were evaluated by a colorimetric method using MTT Kit. At the beginning, $7 \times 10^{3} \mathrm{HDF}$ cells were seeded into each well of a 96-well plate and incubated for $24 \mathrm{~h}$ through which cells are attached to the walls of the wells. Cells were treated with different concentrations $(50,25,10,5,1$, 0.5 and $0.1 \mu \mathrm{g} / \mathrm{ml}$ ) of either the ethanol or the aqueous extracts and incubated for $72 \mathrm{~h}$ at $37^{\circ}$ in $5 \% \mathrm{CO}_{2}$ atmosphere, followed by the MTT assay. After adding
$100 \mu 1 \mathrm{MTT}$ solutions $(5 \mathrm{mg} / \mathrm{ml}$ in Phosphate-buffered saline (PBS)) to each well, cells were incubated for $2 \mathrm{~h}$ and the supernatant was removed. Then, DMSO was added to dissolve the formed formazan crystals and the absorbance was measured at $595 \mathrm{~nm}$ using an ELISA reader. All experiments were done in triplicate and represented as mean $\pm \mathrm{SD}$. The percentage of proliferation after treatment with different extracts concentrations was measured relative to the blank using the following equation:

Percentage of proliferation $=(\mathrm{OD}$ of treated cells/ Average OD of control cells ( $\mathrm{n}=3)) \times 100 \%$

Where $\mathrm{OD}=$ optical density

\section{Scratch assay:}

For the HDFs scratch assays, the cells were incubated in IMDM supplemented with $1 \%$ FPS and $0.1 \%$ BSA. The migration potential of fibroblasts was assessed using the wound healing scratch assay as described by Prince and co-workers ${ }^{[22]}$. The HDFs were cultured until confluency in 6-well culture plates. A scratch was made in the confluent monolayer with a plastic disposable pipette tip $(100 \mu 1)$. Cultures were washed twice with PBS to remove detached cells. After that, fibroblasts were cultured in $50 \mu \mathrm{g} / \mathrm{ml}$ of either ethanol or aqueous extracts in IMDM or left without treatment to serve as control. Each well was photographed directly post scratch formation $\left(\mathrm{t}_{0}\right)$ and every $16 \mathrm{~h}$ until $48 \mathrm{~h}$ passed post treatment, using Primovert microscope. In order to calculate the extent of wound closure; the horizontal distance between the migrating cells from the initial wound position was determined and the photos were analyzed using ${\text { Image }{ }^{\circledR}}^{\circledR}$ NIH, Bethesda, MD). The percentage of wound closure was calculated relative to the area at $\mathrm{t}_{0}$ using the following equation:

Percentage of unhealed wound area $=($ wound area at time (n)/wound area at $\left.\mathrm{t}_{0}\right) \times 100 \%$

Where $\mathrm{n}=0,16,32$ and $48 \mathrm{~h}$.

All measurements were performed in triplicate and presented as mean $\pm \mathrm{SD}$.

\section{Preparation of plant extract-loaded hydrogel formula for in vivo wound healing study}

Hydroxyapatite $(0.5 \mathrm{~g})$ was stirred with $98 \mathrm{ml}$ distilled water until complete dispersion, followed by the addition of plant aqueous extract (in two concentration $2 \%$ and $5 \%$ ). An extract-free formula was used as blank. Twenty-five grams of Pluronic F-127 was 
added into the flask and cooled in the refrigerator for 3-4 $\mathrm{h}$ until the poloxamer is completely dissolved. Chitosan ( $3 \mathrm{~g}$ ) was added under agitation, followed by the addition of $2 \mathrm{ml}$ acetic acid to solubilize chitosan. Finally, the hydrogel consistency that is suitable for the topical application was achieved by drop wise addition with stirring of $100 \mu \mathrm{l}$ of $2 \%$ aqueous glutaraldehyde solution that serves as a cross linker for chitosan.

\section{Excision wound model:}

Sixty healthy Wistar rats of either sex (200-250 g) with no prior drug treatment were used. The animals were acclimatized to laboratory conditions for $7 \mathrm{~d}$ before starting the experiments. All animals were given standard pellet diet and water ad libitum. Throughout the experimentation period, animals were housed individually in cages. This study was conducted in the Experimental Animal House, The University of Jordan

A day before starting the wound healing experiment, the animals' dorsal skin was shaved and the animals were randomly divided into five groups: group 1: Negative control group, untreated animals; group 2: Positivecontrol group, treated with Ialuset ${ }^{\circledR}$ Pluscream; group 3: Treated with blank hydrogel formula; group 4: Treated with hydrogel formula containing $2 \%$ aqueous extract (Low concentration); and group 5: Treated with hydrogel formula containing $5 \%$ aqueous extract (High concentration).

On the next day (d 1), full anesthesia was induced by intraperitoneal injection of a freshly prepared anesthetic mixture composed of $4 \mathrm{ml}$ Ketamine (50\%), $1 \mathrm{ml}$ Xylazine $(20 \%)$ and $5 \mathrm{ml}$ normal saline. The mixture was given to the rats in a dose of $0.12 \mathrm{ml} / 100 \mathrm{mg}$ body weight. A full-thickness excision wound of $15 \times 15 \mathrm{~mm}$ dimensions was then created.

$500 \mu 1$ of each treatment group was measured using a syringe and applied daily on the wound, extending slightly outside the wound area to ensure inclusion of the wound edges. The first application was done directly after the wound induction. Wound area was measured daily, starting from $\mathrm{d} 2$, by tracing the wound edges on a transparent sheet with permanent marker. At the middle of the experimental period ( 7 post-injury), 6 animals of each group where sacrificed and tissue samples of the wound area including the margins were collected and placed directly in formaldehyde for histological analysis. At the end of the experiment (d 14 postinjury), similar tissue samples (from the remaining six animals of each group) were collected. Tissues samples were divided into two groups each of three animals; one group was used for histological analysis and the other group of tissues were placed directly in $0.9 \%$ saline solution and used for tensile strength measurements.

\section{In vivo wound healing characterization:}

Wound area contraction: The surface area of the wound was determined by tracing the wound margins and calculating the wound area using Image ${ }^{\circledR}$ software. The percentage of healed wound area was calculated using the following equation:

Percent of wound healing $=$ (wound area at a given time interval/area of original wound on $\mathrm{d} 1) \times 100 \%$ )

Tensile strength measurement: On d 14 post-injury, completely healed skin samples that included the area were the wound was performed, were removed carefully from each animal under investigation, washed in saline and subjected to tensile strength measurement within one hour of sacrifice. Thickness measurements were taken on a small, shaved area of the skin using a digital caliper. Test samples were produced using a template of $10 \mathrm{~mm}$ wide by $30 \mathrm{~mm}$ long.

The tensile strength was measured using a universal testing machine. The skin samples were fixed in the instrument longitudinally between two jaws. The instrument speed was set at $10 \mathrm{~mm} / \mathrm{min}$ and the measured force $(\mathrm{N})$ per displacement of the skin sample $(\mathrm{mm})$ was recorded.

Histological examination: The skin samples were fixed in paraformaldehyde and mounted into paraffin. A series of $5 \mu \mathrm{m}$ thick paraffin sections were stained with hematoxylin/eosin (H\&E) or Masson's trichrome stains and examined histologically using an optical microscope.

\section{Statistical analysis:}

Data were processed and expressed as mean \pm standard deviation of triplicate experiments using SPSS statistical package version 16.0 (SPSS, Inc.). Analysis of variance (ANOVA) and Bonferroni post-hoc was applied to assess differences between different groups, where $\mathrm{p}<0.01$ was considered statistically significant.

\section{RESULTS AND DISCUSSION}

The presence of certain pathogenic bacterial strains such as Staphylococcus sp., Streptococcus sp., Propionibacterium sp., and Pseudomonas sp. may delay the healing process. On the other hand, strains such as Malassezia sp., Candida sp., and Corynebacterium sp. 
were isolated from uninfected wounds suggesting their non-pathogenic effect or even they might contribute to wound healing ${ }^{[23]}$. Therefore, any successful protocol to deal with wounds should consider also inhibiting the pathogenic bacterial strains.

The aqueous extract of $S$. molle showed better results than the ethanol extract regarding the antibacterial activity. The growth of $C$. freundii and E. fecalis was totally inhibited by the aqueous extract even when using the lowest concentration (i.e., $1.56 \mathrm{mg} / \mathrm{ml}$; fig. 1A), which is similar to the effect of Gentamicin, the antibiotic that was used as a positive control, using the same concentrations. Other bacterial species used in this study reacted differently. The effect of the aqueous extract both on $P$. aurigenosa and $S$. aureus, was similar as the potential minimum bactericidal concentration (MBC) was measured to be $12.5 \mathrm{mg} / \mathrm{ml}$ and subsequently the MIC would be $6.25 \mathrm{mg} / \mathrm{ml}$. The expected MBC and MIC for E. coli were $25 \mathrm{mg} / \mathrm{ml}$ and $12.5 \mathrm{mg} / \mathrm{ml}$, respectively. The least effect of the aqueous extract was noticed on $S$. epidermidis, as the potential MBC reached $50 \mathrm{mg} / \mathrm{ml}$ and the MIC was $25 \mathrm{mg} / \mathrm{ml}$ (fig. 1A). Aqueous extracts of Andrographis paniculata, green chiretta, has antimicrobial ${ }^{[2]}$ and antiviral ${ }^{[25]}$ activities. Additionally, it helps in wound closure in rats after treatment with a $10 \%$ aqueous leaf extract of $A$. paniculate $^{[26]}$. The aqueous extract prepared from the leaves of Camellia sinensis, green tea, exhibited antioxidant ${ }^{[27]}$, anti-inflammatory ${ }^{[28]}$ and antimicrobial ${ }^{[29]}$ activities.

Unlike the effective antimicrobial effect of the aqueous extract, ethanol extract of $S$. molle showed incompetent inhibition of bacterial growth. All the concentrations used $(1.56-100 \mathrm{mg} / \mathrm{ml})$ were not able to inhibit the bacterial growth except for $S$. aureus and E. fecalis. The latter two bacterial strains were inhibited only at the highest concentration of the ethanol extract $(100 \mathrm{mg} / \mathrm{ml}$; fig. 1B). The ethanol extracts of some plants showed good antimicrobial activity especially for pathogenic bacteria that affect wound healing negatively. For example, ethanol extracts of Caesalpinia sappan had high antibacterial activity against, methicillin-resistant $S$. aureus (MRSA), S. aureus, P. aeruginosa, Acinetobacter baumannii, E. coli and Klebsiella pneumonia ${ }^{[30]}$. Similarly, the extracts of Ampelopsis japonica, exhibited antimicrobial, and anticancer ${ }^{[31]}$ activities and the ethanol extracts of its dried roots augmented the healing of cutaneous injury resulted from the hot water and hot steam in rats ${ }^{[32]}$. Ethanol extracts of specific plant parts has showed more than one positive effect on wound healing at its different stages. A good example on that is the root extract from C. sappan also enhanced dermal fibroblast proliferation, migration, and collagen synthesis ${ }^{[33]}$, subsequently improving cutaneous wound healing.

Schinus molle ethanol and aqueous extracts were tested for their possible proliferation effect on HDFs. The percentages of proliferation following treatment for $72 \mathrm{~h}$ with different concentrations of the plant extracts were calculated relative to the control cells (non-treated cells). As shown in fig. 2, both extracts exhibited positive effect on HDFs proliferation. The treatment with the extracts for $72 \mathrm{~h}$ significantly increased the HDFs proliferation percentage in comparison to the control group.

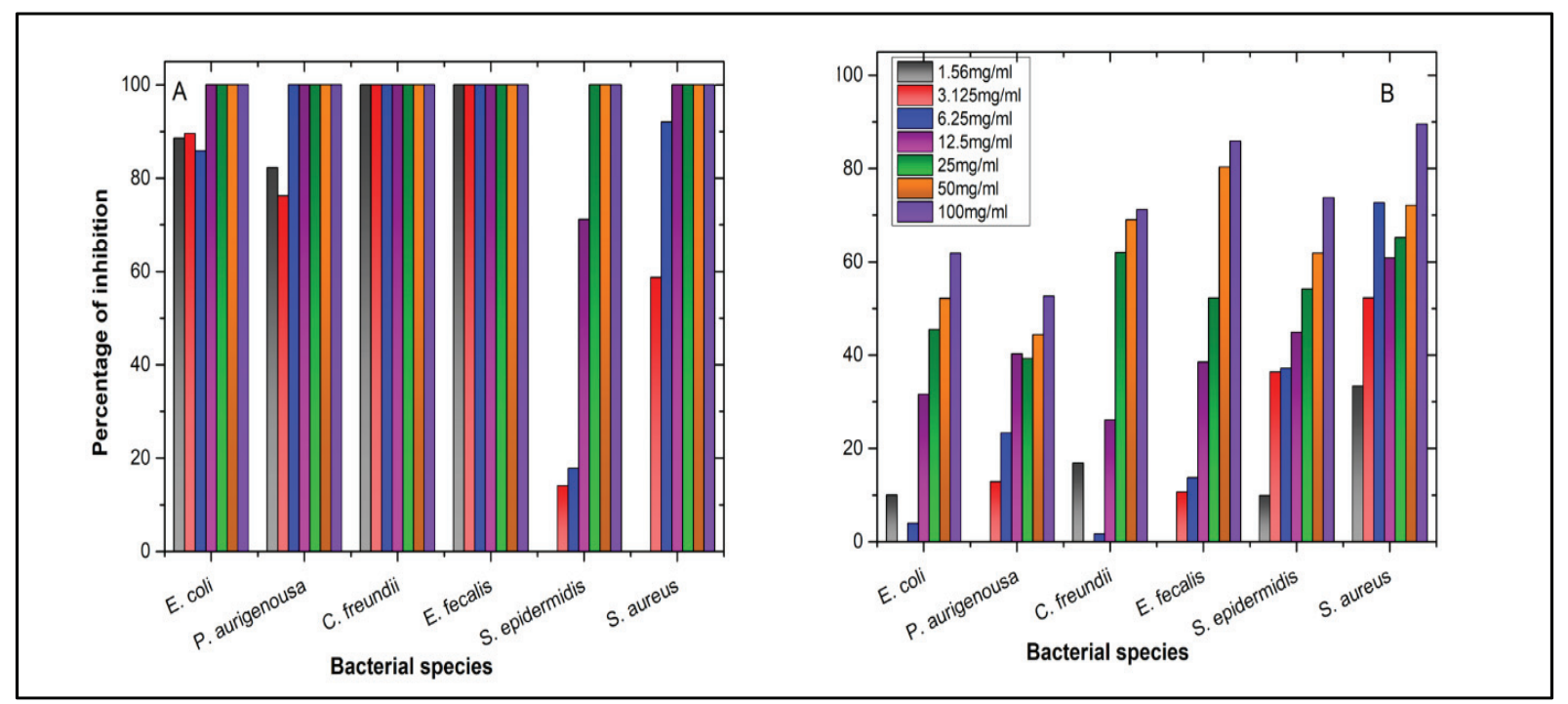

Fig. 1: The antimicrobial effect of the aqueous (a) and ethanol extracts (b), represented as percentage of inhibition, of $S$. molle against 6 different bacterial species. The extracts were used in concentrations ranging from $1.56-100 \mathrm{mg} / \mathrm{ml}$. 
Another test, demonstrating the proliferation-promoting effects of the plant extracts, was performed using scratch assay. In this assay, the injured (scratched) cells were allowed to heal in the presence of $S$. molle ethanol or aqueous extracts and their healing was compared to the untreated (control) cells. The images depicted in fig. 3 clearly show that HDF grown in the presence of either of the extracts healed better compared to the control cells.
The results obtained from the scratch assay (fig. 3) were analyzed using Image $\mathrm{J}^{\circledR}$ software and the wound area was measured. Fig. 4 shows the percent of wound area with time, for the scratched cells treated with the ethanol or aqueous extracts and for the control cells. The percentages were calculated in comparison with the wound area at $t_{0}$. From the above results, it can be concluded that both, the ethanol and aqueous extracts have a positive effect on the wound area.

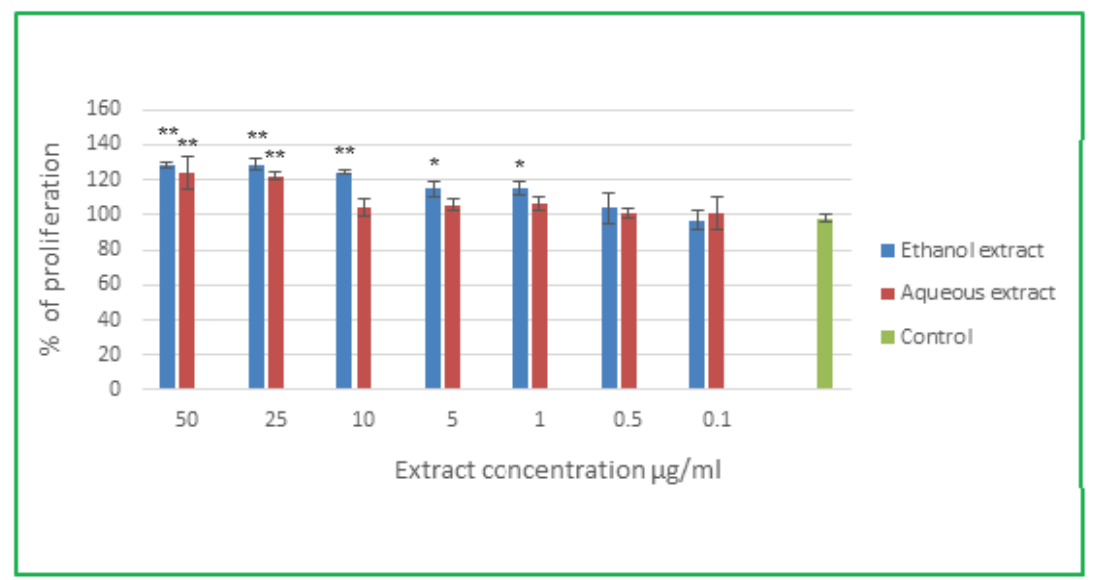

Fig. 2: Effect of various concentrations of ethanol and aqueous extracts of $S$. molle on HDF proliferation after $72 \mathrm{~h}$ incubation period. $* * \mathbf{p}<0.01, * \mathbf{p}<0.05$ compared to the control.

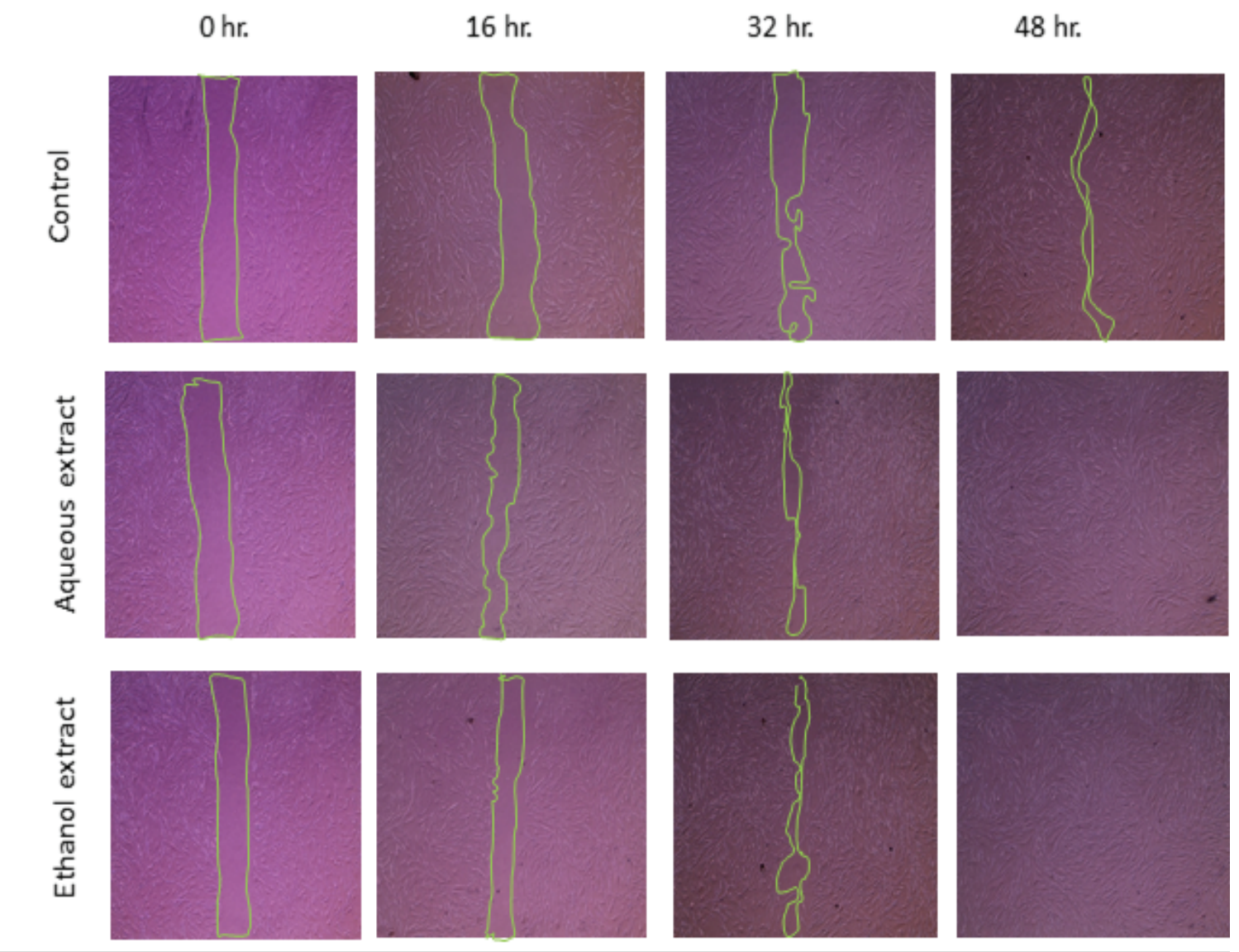

Fig. 3: Representative microscopy images of HDF during the scratch assay. Cells were either untreated (top row) or treated with 50 $\mu \mathrm{g} / \mathrm{mL}$ of aqueous (middle row) or ethanol (bottom row) extracts, Images were taken at $0,16,32$, and $48 \mathrm{~h}$ post-scratch. 
It is well known that the scratched cells can heal by two different mechanisms, either by proliferation i.e. the number of the cells increase to cover the wound area, or by migration of the cells next to the wound edges by elongation of their shape to reach the other side of the wound while retaining the confluency of the cells ${ }^{[34]}$. From the scratch assay results it was obvious that there is no change in the shape of the cells at the edges of the wound (fig. 3). Additionally, the positive effect of the plant extracts on the HDFs proliferation strengthens the suggested hypothesis that the proliferation is the predominant wound healing mechanism.

Similar findings were reported by Schmidt and coworkers ${ }^{[14]}$. This group of researchers have conducted a comprehensive study and tested the in vitro wound healing potential of twelve Brazilian plants' extracts, using scratch assay. They found that the $S$. molle extract was one of most effective species in their study.

The wound healing effects of the $S$. molle aqueous extract in two different concentrations, high (5\%) and low $(2 \%)$ were studied using a full-thickness excision skin wound model in rats. The extracts were incorporated in a hydrogel formula composed of crosslinked chitosan, hydroxyapatite and pluronic F127 in order to facilitate topical application to the wounds. The wound area was measured daily over $14 \mathrm{~d}$ postexcision and the percentage of healed wound area was calculated. The results are shown in fig. 5.

Significant improvement in wound closure was observed for the treated animals in comparison with the control group (fig. 5A and fig. 5B). This effect is seen mainly in the early stages of wound healing, specifically, until day 5 post treatment. Later, the wound size of all groups was not significantly different and the wounds were completely closed $14 \mathrm{~d}$ after the excision in most of the animals under investigation.

These results indicate that the $S$. molle aqueous extract has wound healing property in vivo where the high concentration ( $5 \%$ ) exhibited better results. Moreover, during the first period of the experiment, a significant increase in the wound closure rate was observed for the animals group treated with the blank formula (fig. 5A and fig. 5B); indicating a positive influence of the used formula.

The tensile strength of the freshly isolated skin samples from the animals under investigation was measured. Test samples were produced in triplicate. Stress $\left(\mathrm{N} / \mathrm{mm}^{2}\right)$ was determined by normalizing the load for initial cross-sectional area and strain was determined by normalizing the change in displacement for initial sample length. The stress versus strain curves revealed differences in skin properties among all treated groups, blank formula and controls (fig. 6).

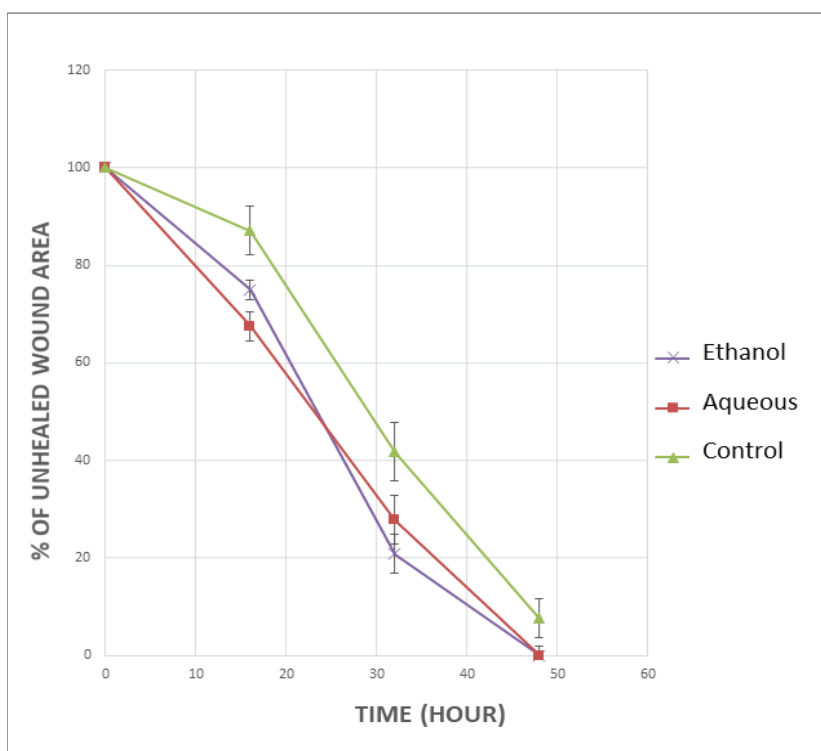

Fig. 4: Percentage of the unhealed wound area of the scratched HDFs with time for the cells treated with ethanol or aqueous extract $(50 \mu \mathrm{g} / \mathrm{ml})$ compared to the control (untreated) cells. Data shown as mean $\pm S D, n=3$.

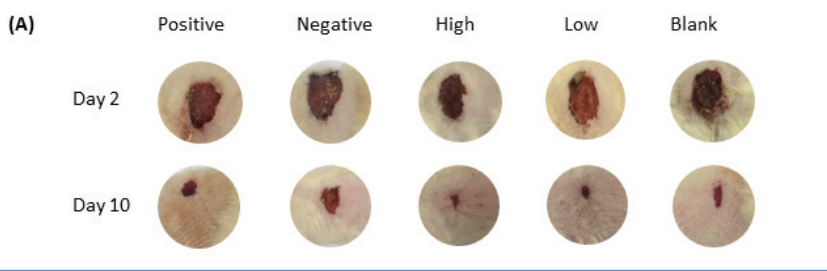

(B)

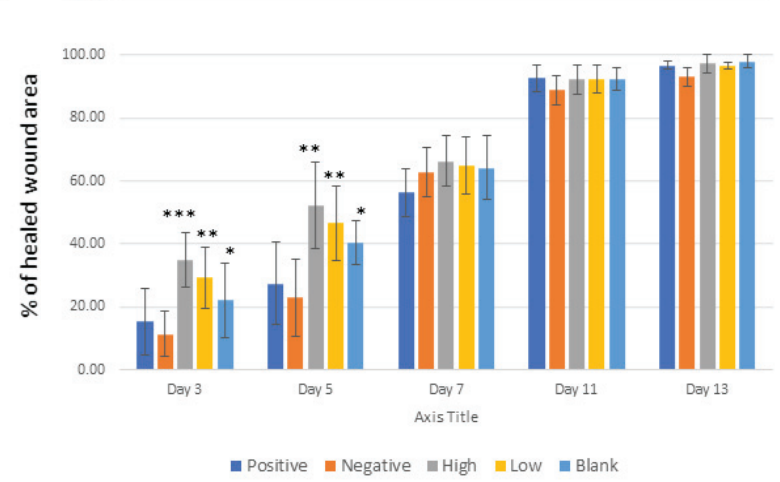

Fig. 5: (A) Representative photographs of the full thickness skin wounds and subsequent wound contraction on $\mathrm{d} 2$ and 10 in the positive control group, negative control group, group treated with formula containing $5 \%$ extract (High concentration), with $2 \%$ extract (Low concentration) and blank formula group. Scale bar: $2 \mathrm{~cm}$. (B) Quantification of the wound area in the different groups. Data shown as mean $\pm \mathrm{SD}, * * * \mathrm{p}<0.005$, $* * \mathbf{p}<\mathbf{0 . 0 0 1}, * \mathbf{p}<\mathbf{0 . 0 1}$. 
The enhancement in the tensile strength was best in the groups treated with the formula containing $5 \%$ of the plant extract. This confirms that the chemical constituents of the aqueous extract in higher concentration might be responsible for this strengthening of the skin observed by increasing the force sustained per unit area of the skin samples.

Tissue samples collected from the animals of different groups were treated and stained for histological analysis according the usual procedure. Tissue samples collected on $\mathrm{d} 7$ post-injury, as seen in fig. 7, showed a prominent crust formation, with prominent granulation

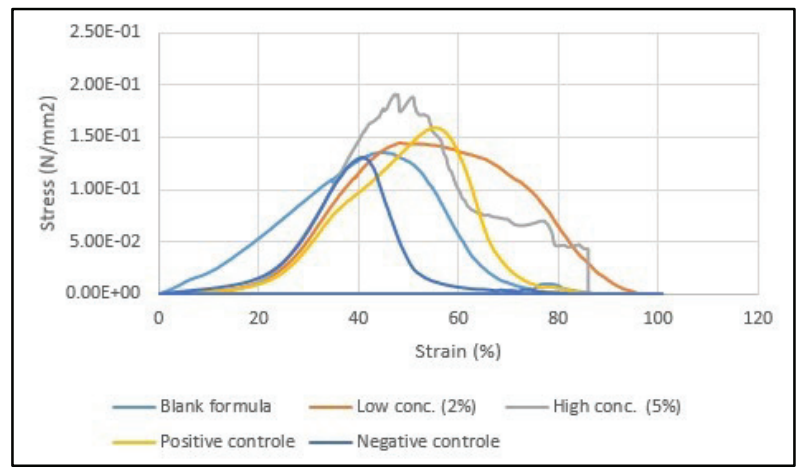

Fig. 6: Tensile strength results of the skin samples on $\mathrm{d} 14$ in the positive control group, negative control group, group treated with formula containing $5 \%$ extract (High concentration), with $2 \%$ extract (Low concentration) and blank formula group. The results of tensile strength for 3 different samples of each group where recorded, averaged and represented. tissue and neovascularization, inflammation, minimal epithelization and minimal fibrosis as proven by Masson trichrome special stain.

The samples collected at the end of the experiment ( $d$ 14 post-injury) are represented in fig. 8. A comparison of these samples with those collected at $d 7$ of the experiment (fig. 7) demonstrate clearly the progression in wound healing characterized by a decrease in crust formation, granulation tissue and inflammation. Neovascularization, better epithelization and more fibrosis were also observed.

Re-epithelialization and neovascularization of epidermis and sub-epidermal cells were seen in regenerated tissue of the animals treated with the hydrogel formula containing the plant extract. Also, fibroblast proliferation connecting skin, was observed at the site of wound healing in positive control treated animals and those treated with the $S$. molle aqueous extract including formula that showed normal epidermis with presence of increased amount of the fibers observed as intense blue color for the tissue samples as proven by Masson trichrome special stain of the treated animals (fig. 8D \& fig. 8F) if compared with the negative control group (fig. 8J). This is a strong indication for the wound healing potential of $S$. molle areal parts aqueous extract and justifies the traditional use of this plant for wound healing in South American traditional medicine ${ }^{[8,14-17]}$.

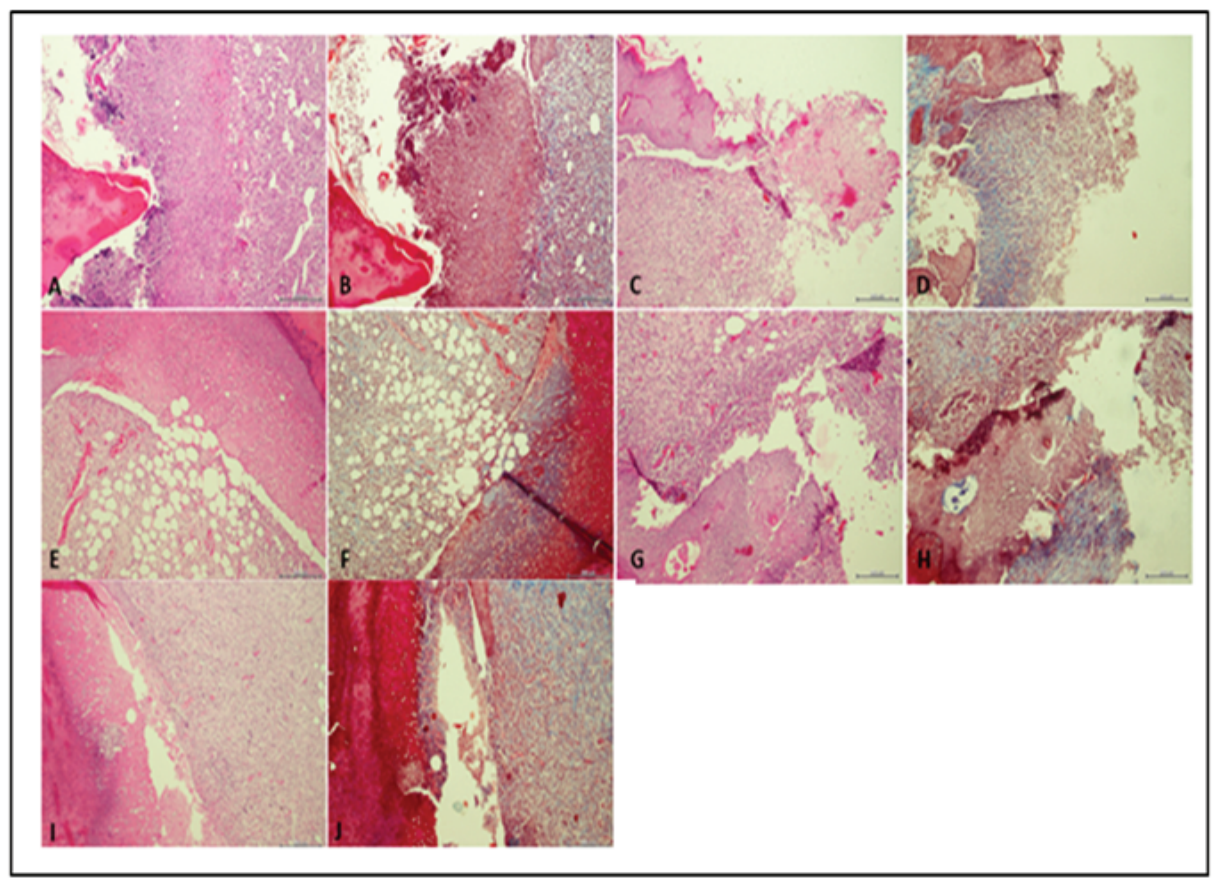

Fig. 7: Tissue samples collected 7 d post-injury; stained with: H\&E, X20 (A, C, E, G and I), Masson trichrome special stain X20, blue color indicates fibrosis (B, D, F, H and J). Samples were collected from animals treated with: Blank formula (A and B), Formula with $5 \%$ extract (C and D), Formula with $2 \%$ extract (E and F), Negative control ( $G$ and $H)$ and Positive control (I and J). Fibrosis (black arrow), inflammation, neovascularization and granulation tissue (Red arrow), epithelization (yellow arrow). 


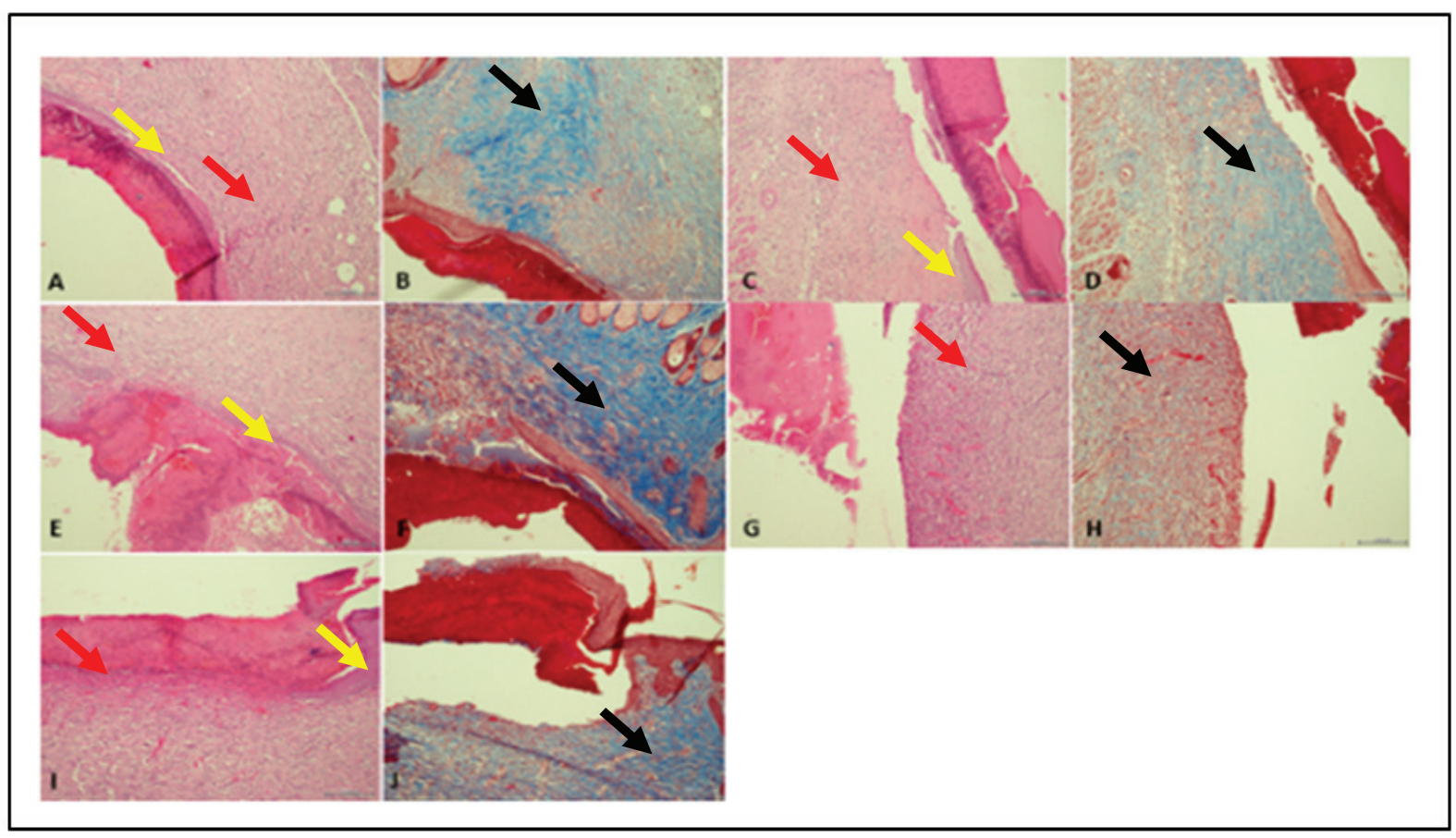

Fig. 8: Tissue samples collected 14 d post-injury; H\&E, X20 (A, C, E, G and I), Masson trichrome special stain X20, blue color indicates fibrosis (B, D, F, H and J). Samples were collected from animals treated with: Blank formula (A and B), Formula with $5 \%$ extract (C and D), Formula with $2 \%$ extract ( $E$ and F), Negative control (G and $H$ ) and Positive control (I and J).

Fibrosis (black arrow), inflammation, neovascularization and granulation tissue (Red arrow), epithelization (yellow arrow).

\section{CONCLUSION}

Would healing is a complex process that involves the interplay and interaction of various components including chemotaxis, whereby different cells including inflammatory cells is recruited to the site of the injury. Myogenesis and angiogenesis or neovascularization, involve the activation of fibroblasts and the initiation of new blood vessels formation, respectively ${ }^{[35]}$. In addition a plethora of cytokines are released to enhance the various processes and components of healing including epidermal growth factor (EGF), fibroblast growth factor (FGF), platelet-derived growth factor (PDGF), transforming growth factor (TGF) $-\alpha$ and $-\beta$. Many of these growth factors are actually involved in more than one function. These usually exert their function through receptor-ligand binding and subsequent activation of the desired cell to undergo the desired function. These cytokines and growth factors can act through an autocrine, paracrine and endocrine fashion ${ }^{[36]}$.

The wound healing potential of $S$. molle ethanol and aqueous extracts were demonstrated in vitro by HDF proliferation and scratch assays. A hydrogel formula, with a suitable consistency, good spreadability and capability to form a barrier layer above the injured area, has been formulated and enriched with the plant aqueous extract to assess the wound healing potential of $S$. molle aqueous extract in vivo. In these experiments, re-epithelialization, neovascularization of epidermis and sub-epidermal cells together with fibroblast proliferation were seen in regenerated tissue of the animals treated with the used formula containing the plant extract. Additionally, an increase in the tensile strength for the skin samples of the animal groups treated with the formulated plant aqueous extract was observed. This increase in the tensile strength of the skin samples of treated animals supports further support the wound healing potential of $S$. molle.

\section{Conflict of interest:}

The authors declare no conflict of interest

\section{Acknowledgement:}

The authors thank the Deanship for Scientific Research, The University of Jordan for the financial support of this study.

\section{Ethical statement:}

All applicable guidelines for the care and use of animals were followed. The experimental protocols involving the rats used in this study were reviewed and approved by the Scientific Research Ethics Committee, The University of Jordan (decision number 9/2018-2019). 


\section{REFERENCES}

1. Singer AJ, Clark RA. Cutaneous wound healing. N Engl J Med 1999;341(10):738-46.

2. Eming SA, Martin P, Tomic-Canic M. Wound repair and regeneration: mechanisms, signaling, and translation. Sci Transl Med 2014;6(265):265sr6.

3. Ryan TJ. Infection following soft tissue injury: its role in wound healing. Curr Opin Infect Dis 2007;20(2):124-8.

4. Edwards R, Harding KG. Bacteria and wound healing. Curr Opin Infect Dis 2004;17(2):91-6.

5. Kramer FL. The pepper tree, Schinus molle L. Econ Bot 1957;11(4):322-6.

6. Belhamel K, Abderrahim A, Ludwig R. Chemical composition and antibacterial activity of the essential oil of Schinus molle L. grown in Algeria. Int J Essen Oil Ther 2008;2(4):175-7.

7. Ono M, Yamashita M, Mori K, Masuoka C, Eto M, Kinjo J, et al. Sesquiterpenoids, triterpenoids, and flavonoids from the fruits of Schinus molle. Food Sci Technol Res 2008;14(5):499.

8. Schulze-Kaysers N, Feuereisen MM, Schieber A. Phenolic compounds in edible species of the Anacardiaceae family-a review. RSC Adv 2015;5(89):73301-14.

9. Barbosa LC, Demuner AJ, Clemente AD, Paula VF, Ismail F. Seasonal variation in the composition of volatile oils from Schinus terebinthifolius Raddi. Quim Nova 2007;30(8):195965.

10. Ibrahim B, Al-Naser Z. Analysis of fruits Schinus molle extractions and the efficacy in inhibition of growth the fungi in laboratory. Int J Chemtech Res 2014;6(5):2799-806.

11. Yueqin Z, Recio MC, Máñez S, Giner RM, Cerdá-Nicolás M, Ríos JL. Isolation of two triterpenoids and a biflavanone with anti-inflammatory activity from Schinus molle fruits. Planta Med 2003;69(10):893-8.

12. Bendaoud H, Romdhane M, Souchard JP, Cazaux S, Bouajila J. Chemical composition and anticancer and antioxidant activities of Schinus molle L. and Schinus terebinthifolius Raddi berries essential oils. J Food Sci 2010;75(6):C466-72.

13. Marzouk MS, Moharram FA, Haggag EG, Ibrahim MT, Badary OA. Antioxidant flavonol glycosides from Schinus molle. Phytother Res 2006;20(3):200-5.

14. Schmidt C, Fronza M, Goettert M, Geller F, Luik S, Flores EM, et al. Biological studies on Brazilian plants used in wound healing. J Ethnopharmacol 2009;122(3):523-32.

15. Eryigit T, Yildirim B, Ekici K, Çirka M. Chemical composition, antimicrobial and antioxidant properties of Schinus molle L. Essential oil from Turkey. J Essent Oil Bear Plants 2017;20(2): 570-7.

16. Gomes V, Agostini G, Agostini F, Dos Santos AA, Rossato M. Variation in the essential oils composition in Brazilian populations of Schinus molle L.(Anacardiaceae). Biochem Syst Ecol 2013;48:222-7.

17. Hayouni EA, Chraief I, Abedrabba M, Bouix M, Leveau JY, Mohammed H, et al. Tunisian Salvia officinalis L. and Schinus molle L. essential oils: Their chemical compositions and their preservative effects against Salmonella inoculated in minced beef meat. Int J Food Microbiol 2008;125(3):242-51.

18. Park JW, Hwang SR, Yoon IS. Advanced growth factor delivery systems in wound management and skin regeneration. Molecules 2017;22(8):1259.

19. Aboalhaija A, Amro R, Abaza I, Khalil E, Al-Aboudi A, AbuZarga M, et al. Schinus molle L. Collected from Jordan and Turkey: Essential Oil Composition and Anticholinesterase Activity. J Essent Oil Bear Plants 2019;22(3):704-16.
20. Aboalhaija NH, Awwad O, Khalil E, Abbassi R, Abaza IF, Afifi FU. Chemodiversity and Antiproliferative Activity of the Essential Oil of Schinus molle Growing in Jordan. Chem Biodivers 2019;16(11):e1900388.

21. Diaz C, Quesada S, Brenes O, Aguilar GCicció JF. Chemical composition of Schinus molle essential oil and its cytotoxic activity on tumour cell lines. Nat Prod Res 2008;22(17):152134.

22. Prince T, McBain AJ, O'Neill CA. Lactobacillus reuteri protects epidermal keratinocytes from Staphylococcus aureusinduced cell death by competitive exclusion. Appl Environ Microbiol 2012;78(15):5119-26.

23. Kalan L, Zhou M, Labbie M, Willing B. Measuring the microbiome of chronic wounds with use of a topical antimicrobial dressing-a feasibility study. PloS one 2017;12(11):e0187728.

24. Rahman MM, Ahmad SH, Mohamed MT, Ab Rahman MZ. Antimicrobial compounds from leaf extracts of Jatropha curcas, Psidium guajava, and Andrographis paniculata. Sci World J 2014;2014.

25. Wiart C, Kumar K, Yusof MY, Hamimah H, Fauzi ZM, Sulaiman M. Antiviral properties of ent-labdene diterpenes of Andrographis paniculata nees, inhibitors of herpes simplex virus type 1. Phytother Res 2005;19(12):1069-70.

26. Al-Bayaty FH, Abdulla MA, Hassan MI, Ali HM. Effect of Andrographis paniculata leaf extract on wound healing in rats. Nat Prod Res 2012;26(5):423-9.

27. Espinosa C, López-Jiménez JA, Pérez-Llamas F, Guardiola FA, Esteban MA, Arnao MB, et al. Long-term intake of white tea prevents oxidative damage caused by adriamycin in kidney of rats. J Sci Food Agric 2016;96(9):3079-87.

28. Chen BT, Li WX, He RR, Li YF, Tsoi B, Zhai YJ, et al. Antiinflammatory effects of a polyphenols-rich extract from tea (Camellia sinensis) flowers in acute and chronic mice models. Oxid Med Cell 2012;2012.

29. Ibrahim A, Noman Albadani R. Evaluation of the potential nephroprotective and antimicrobial effect of Camellia sinensis leaves versus Hibiscus sabdariffa (in vivo and in vitro studies). Adv Pharmacol Sci 2014;2014.

30. Temrangsee P, Kondo S, Itharat A. Antibacterial activity of extracts from five medicinal plants and their formula against bacteria that cause chronic wound infection. J Med Assoc Thai=Chot Mai Het Thang Phaet 2011;94:S166-71.

31. Nho KJ, Chun JM, Kim DS, Kim HK. Ampelopsis japonica ethanol extract suppresses migration and invasion in human MDA-MB-231 breast cancer cells. Mol Med Rep 2015;11(5):3722-8.

32. Lee K, Lee B, Lee MH, Kim B, Chinannai KS, Ham I, et al. Effect of Ampelopsis Radix on wound healing in scalded rats. BMC Complement Altern Med 2015;15(1):1-9.

33. Tewtrakul S, Tungcharoen P, Sudsai T, Karalai C, Ponglimanont $\mathrm{C}$, Yodsaoue O. Antiinflammatory and wound healing effects of Caesalpinia sappan L. Phytother Res 2015;29(6):850-6.

34. Mohammedsaeed W, Cruickshank S, McBain AJ, O’Neill CA. Lactobacillus rhamnosus GG lysate increases reepithelialization of keratinocyte scratch assays by promoting migration. Sci Rep 2015;5(1):1-1.

35. Ganapathy N, Venkataraman SS, Daniel R, Aravind RJ, Kumarakrishnan VB. Molecular biology of wound healing. J Pharm Bioallied Sci 2012;4(Suppl 2):S334.

36. Falanga V. Growth factors and wound healing. J Dermatol Surg Oncol 1993;19(8):711-4. 